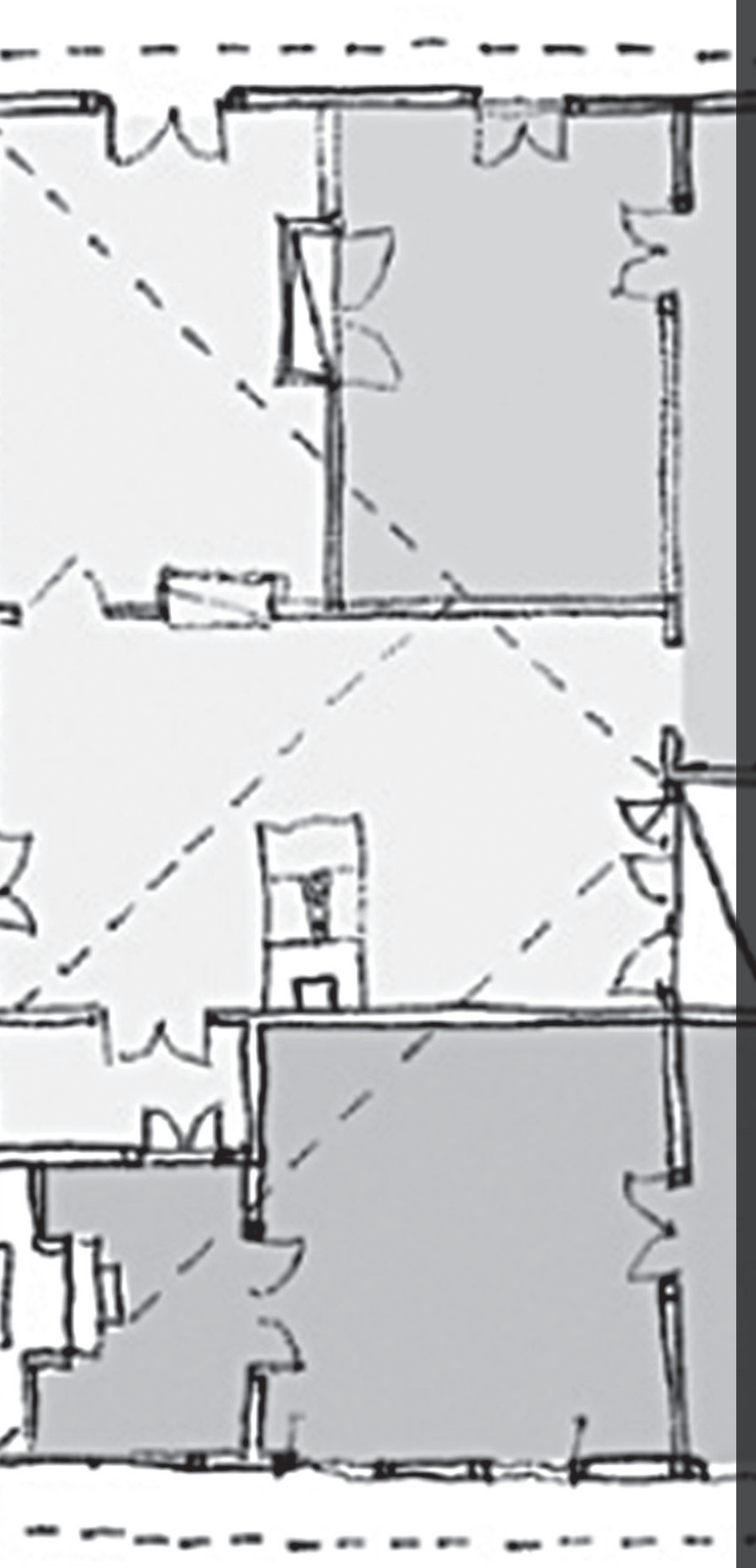

1. Este artigo é parte integrante da pesquisa de mestrado em desenvolvimento na Universidade Presbiteriana Mackenzie, intitulada "O patrimônio arquitetônico rural do café em Ribeirão Preto (1870-1930): um reconhecimento arquitetônico".Tem bolsa mérito Mackpesquisa, e está sendo orientada pela Prof. ${ }^{a}$ Dr. ${ }^{a}$ Ruth Verde Zein.

2. Mestranda em Arquitetura e Urbanismo pela Universidade Presbiteriana Mackenzie. 


\title{
AS MUDANÇAS NA CASA \\ RURAL DO OESTE PAULISTA \\ NO SÉCULO XIX: \\ A PRESENÇA DO PITORESCO ${ }^{1}$
}

CHANGES INTHE HOUSE OF RURAL WEST PAULISTA IN THE

NINETEENTH CENTURY: THE PRESENCE OF PICTURESQUE

Ana Carolina Gleria²

\section{Resumo}

Este artigo visa a discutir as transformações ocorridas na arquitetura rural, ligada ao ciclo econômico cafeeiro do Oeste Paulista, em especial a zona da Companhia Mogiana de Estrada de Ferro, no último quartel do século XIX. Propõe-se considerar as sedes de fazenda do referido período, considerando o conceito de pitoresco, como é descrito e estudado pela teoria e crítica de arte e arquitetura e sua possível aplicação em estudos específicos de caso de algumas edificações rurais, remanescentes desse Período do Ciclo Cafeeiro, na região do Oeste Paulista.

Palavras-chave: Pitoresco; Arquitetura rural paulista; Fazendas de café.

\begin{abstract}
This paper discusses on the changes occurred in rural architecture, related to the economic cycle of coffee in the west of São Paulo, specially the area of the Company Mogiana Railroad, in the last quarter of the nineteenth century. It is proposed to consider the central farmhouse of the referred period considering the concept of picturesque, as it is described and studied by theory and criticism of art and architecture and its possible application in specific case studies of some rural buildings, remnants from this period of the cycle of coffee, in the region of Oeste Paulista.
\end{abstract}

Key words: Picturesque; Rural São Paulo architecture; Farms coffee. 
A expansão das terras de produção cafeeira para o interior do Estado de São Paulo, que ficou conhecida como "marcha para o Oeste", resulta, segundo Monbeig (1984), do declínio da produção cafeeira na região do Vale do Paraíba devido ao esgotamento dos solos desgastados pelo modo de plantio. Outro fator característico desse declínio foi a Abolição, visto que a mão de obra dessas propriedades era composta de quase $70 \%$ de escravos. Após esgotar a região do Vale do Paraíba, Ferrão (2004) aponta que, já na década de 1870, seria também superada a fronteira de produção cafeeira na região do antigo "quadrilátero do açúcar", denominação dada pelo historiador Alfredo Elis Júnior para o território compreendido entre as cidades de Mogi-Guaçu, Jundiaí, Sorocaba e Piracicaba, avançando para a região do Oeste Paulista, inclusive graças à expansão da infraestrutura de transportes, em especial pela rede ferroviária, viabilizando economicamente a exportação do café pelo Porto de Santos.

Monbeig (1984) afirma que a Companhia de Estradas de Ferro da Mogiana, fundada em 1872, pretendia, em seus planos iniciais, atingir Cuiabá, no norte de Mato Grosso, mas terminou seguindo em direção ao Triângulo Mineiro, seguindo, portanto, o percurso do café. Assim, a estrada de ferro partiu de Campinas, dirigiu-se a Mogi-Guaçu, depois Casa Branca (atingida em 1880), depois Ribeirão Preto (1883), o rio Grande (1887) e Araguari (1900).

Ferrão (2004) compara a produção cafeicultora das fazendas do Oeste Paulista com a das fazendas do Vale do Paraíba, com foco em seus aspectos socioeconômicos,
Figura 1 • Evolução da ferrovia no Estado de São Paulo. Fonte: Matos, 1981, p. 171.

\section{a evoldẹ̃o gerroviaria de são pavlo [1]}

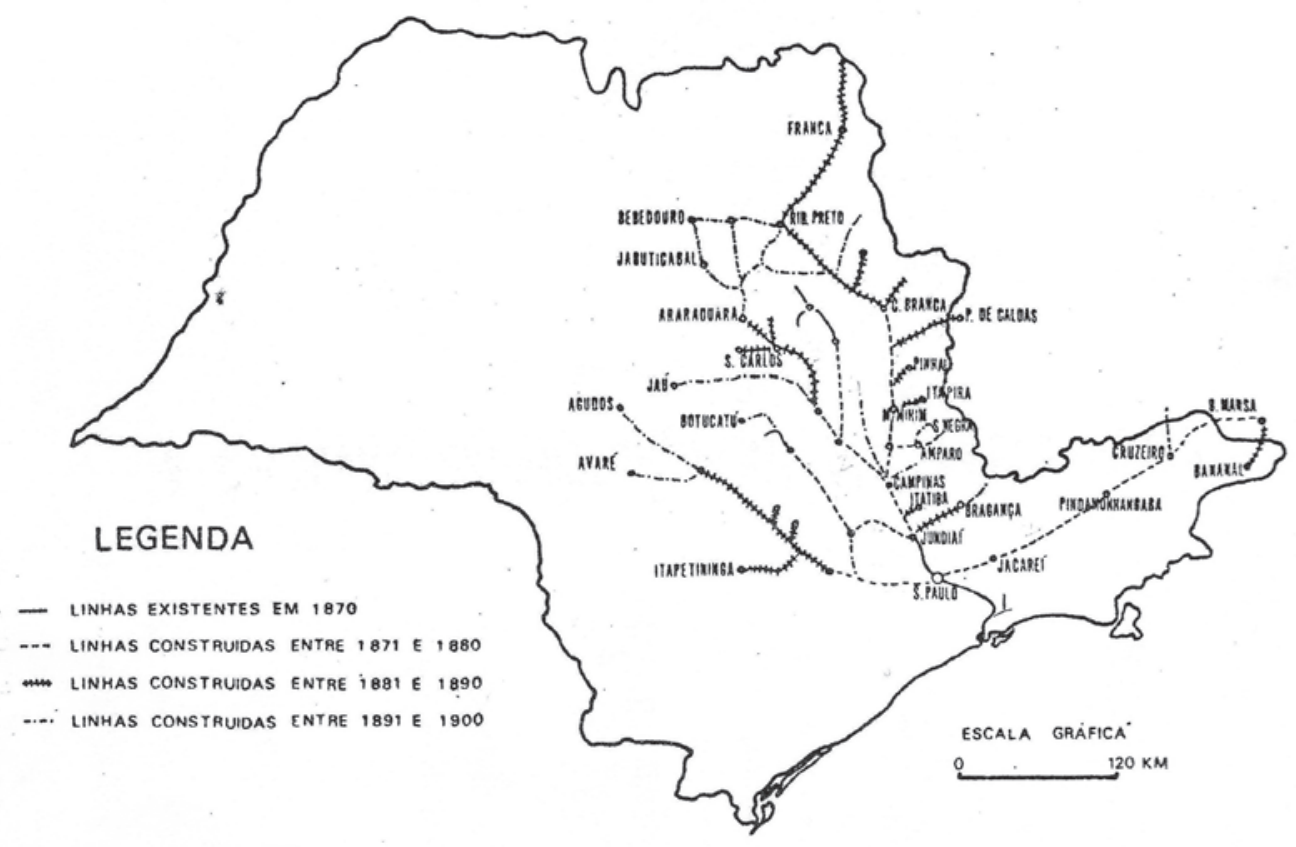

Cadernos de Arquitetura e Urbanismo, v.20, n.26, $1^{0}$ sem. 2013 
considerando-os como momentos distintos e relevantes da emergência do capitalismo no Brasil. Entre os pontos que enfatiza, estão: a transformação da mentalidade tradicional de administração das propriedades em uma mentalidade empresarial capitalista; a passagem da aristocracia escravocrata e conservadora a uma elite imigrantista e liberal; a iniciação dos fazendeiros no ativismo, na prática política; a substituição da ideologia monárquica pela ideologia republicana; a conversão da unidade de produção tradicional (fazenda) em unidade de produção capitalista (empresa), entre outros aspectos.

Entretanto, ao abordar a arquitetura das casas-sedes dessas fazendas, Ferrão (2004) considera que tanto aquelas construídas como aquelas ampliadas no período de 1860 a 1930 mantinham ainda o "partido tradicional" com pequenas modificações. Esse "partido tradicional", definido por Luís Saia (1972, p. 187) com a escolha da Fazenda Pau d'Alho como "exemplar clássico", tem seu ponto de partida na habitação do engenho, com seu acoplamento das áreas de trabalho, e ao partido da casa mineira, com suas relações entre níveis de implantação, caracterizando o alpendrado extensivo que termina em uma capela como procedência dos engenhos, e também a implantação da casa-sede em relação ao terreiro e a senzala, permitindo uma fácil fiscalização dos escravos. A análise de Ferrão (2004) não chega a detalhar esse tema, diante de seu enfoque voltado para a "arquitetura da produção", ou seja, os edifícios funcionais anexos à sede, tais como as tulhas e as casas de máquinas.

Em parcial oposição ao pensamento de Ferrão (2004) está a tese de doutorado de Daici Ceribelli de Freitas (1994), denominada "Os signos da modernidade nos cafezais", defendida na Faculdade de Artes Plásticas da Universidade de São Paulo. Trata-se de um estudo sobre a arquitetura rural do café na região de Ribeirão Preto no último quartel do século XIX e começo do século XX. Nela, a pesquisadora analisa os conjuntos arquitetônicos rurais remanescentes da região de Ribeirão Preto de 1874 a 1930, comparando-os também aos conjuntos rurais anteriores, da mesma região, que lhe permitem afirmar haver mudanças significativas nas construções das sedes de fazendas, que seriam consequência do processo de modernização da arquitetura rural nessa região, durante o período. Freitas (1994, p. 8) entende que as fazendas de café da região de Ribeirão Preto são fruto de um "projeto moderno" baseado nas ideias de racionalidade, funcionalidade, conforto, privacidade e intimidade; mas aponta que, apesar das transformações resultantes desses novos interesses, "a velha arquitetura regional de origem mineira" ainda se faz presente no substrato dessas arquiteturas.

Este artigo corrobora e amplia as constatações de Freitas (1994), uma vez que considera que as mudanças ocorridas na arquitetura rural do Oeste Paulista não apenas levam em conta processos econômicos de "modernização", a que também certamente estão submetidas, mas igualmente busca compreendê-las, também de maneira abrangente, à luz das transformações artísticas e estéticas que ocorrem nesse 
período, e que repercutirão em um debate mundial sobre a necessidade de refundação dos preceitos estéticos da arquitetura, uma vez abandonada a base até então inabalável da tradição clássica que veio estruturando o pensamento arquitetônico a partir do Renascimento.

Segundo Benévolo (1974), durante o século XVIII, começa-se a negar a validade universal das regras ligadas o classicismo, num movimento que, aos poucos, levará à desintegração do sistema cultural clássico. Argan (2006) confirma que, a partir de meados do século XVIII, a prática manualística baseada nos tratados estabelecidos na época do Renascimento ao Barroco vai sendo substituída por teorias da arquitetura fundamentadas na filosofia da arte e na estética, e que a cultura do lluminismo se define pela censura à tradição.

Entretanto, para a compreensão mais acurada dos processos de transformação estética das sedes das fazendas cafeeiras do Oeste Paulista em fins do século XIX e princípios do XX, a discussão não será centrada tanto no pensamento racionalista francês, pois a arquitetura dessas casas não se filia ao movimento neoclássico, como foi o caso de uma parte das fazendas cafeeiras fluminenses (ROCHA-PEIXOTO, 2000). ${ }^{3}$ Compreende e explora o pensamento empírico inglês, que, baseado no conceito de natureza, gerou as noções de pitoresco e sublime, e cujas manifestações arquitetônicas se filiam ao ecletismo e à arquitetura dita "de chalé".

\section{O pitoresco}

Para a contextualização sobre o pitoresco, serão abordados prioritariamente três autores. Procurou-se estudar autores que abordassem o tema do pitoresco a partir de sua aplicação na arquitetura, porém cabe aqui a ressalva de este artigo ser parte integrante de pesquisa de mestrado em desenvolvimento, portanto, ao longo deste processo, outros autores estudados poderão compor esta fundamentação teórica.

Kruft (1994), com uma visão panorâmica, inserindo o pensamento pitoresco na contextualização do período, afirma que esse pensamento nasceu nas grandes propriedades rurais aristocráticas da Inglaterra, no final do século XVIII, combinando os conceitos de paisagismo, pintura e arquitetura. Collins (1978) aprofunda essas definições, colocando que essa nova teoria abrangeria todas as artes, embora privilegiasse principalmente a literatura e a pintura paisagística. Collins considera a teoria estética de meados do século XVIII como se baseando em três categorias: beleza, sublimidade e pitoresco. O último autor tratado será Downing (1969), arquiteto muito divulgado e reconhecido, que adota esses conceitos e os aplica de forma consolidada em seu manual de construção, visando a orientar os projetos de habitações rurais em meados dos século XIX.

Segundo Kruft (1994), o pensamento pitoresco nasceu nas grandes propriedades rurais aristocráticas da Inglaterra, no final do século XVIII, combinando os conceitos de paisagismo, pintura e arquitetura. Para o autor, uma importante figura para a evolução deste conceito foi William Gilpin (1724-1804), artista que publicou uma série de estudos sobre a beleza do
3. Também Benincasa (2008) ressalta a presença, nas casas do início do século XIX localizadas no Vale do Paraíba, de intenções plásticas e preceitos estéticos ditos neoclássicos, introduzidos pela chegada da Missão Francesa no Rio de Janeiro; mas esclarece que, assim mesmo, essas edificações ainda se afinam com os preceitos do Período Colonial, principalmente no que se refere à materialidade da construção. 
pitoresco, definindo-a como a união entre simplicidade e variedade, às quais as ideias brutas sempre contribuem. Outros autores, que, para Kruft (1994), aqueceram a discussão sobre o tema foram Uvedale Price (1747-1829), Richard Payne Knight (1750-1824) e Humphry Repton (1752-1818).

Collins (1978) sustenta que, através de todo o período de 1750 a 1950, a teoria da arquitetura foi dominada por fatores mais estritamente relacionados com a arquitetura doméstica. Coloca a vila romântica, do início do século XIX, como um paradigma para a arquitetura de toda a época, apresentando características como assimetria, irregularidade na planta, que se perpetuaram e hoje fazem parte do conceito geral da arquitetura contemporânea.

Para o autor, a nova teoria estética compreende aparentemente todas as artes, mas se baseava principalmente em duas dela: a literatura e a pintura paisagística. Porém, até meados do século XVIII, essa influência não apareceu diretamente na arquitetura, estando suas primeiras atitudes presentes no pensamento inglês de arte e natureza. Os estudos do início do século de Joseph Addison referentes à visão e à imaginação representam a base da teoria estética, pois a partir de uma tese básica geraram uma filosofia extensa que englobava todas as artes no ano de 1790. Na arquitetura, as publicações de Archibald Alison sobre gosto e a natureza representavam esse pensamento.

Na comparação entre alguns autores, Collins (1978) observa que, embora o valor atribuído às categorias beleza, sublimidade e pitoresco, as emoções estéticas mais comoventes, não derivam da beleza, mas da sublimidade e do pitoresco. A sublimidade se mostra presente com frequência na poética, porém, na arquitetura, apresenta um grau de dificuldade elevado, principalmente em escalas menores, de modo que o valor estético que teve mais influência sobre a arquitetura do século XIX doméstica não era o sublime, mas o pitoresco.

Para Patetta (1997), o sublime depende do fato de reencontrar os princípios da fantasia, do caráter passional da arte, do reconhecimento da invenção e dos processos criativos, e contra a adoção rigorosa dos cânones. Para o autor, as publicações já mencionadas de Addison se resumem a formulações teóricas do empirismo inglês de Berkeley e Locke, que pela revalorização das sensações, do sentimento e da sensibilidade, orientam a crítica da arte e o prazer estético de basear-se no psicologismo empírico e na imaginação.

Patetta (1997) menciona, ainda, Edmund Burke e sua publicação de 1756 sobre a investigação da origem do belo e do sublime, na qual os coloca como categorias estéticas opostas. O belo, para Burke, estaria ligado ao prazer, e o sublime estaria ligado à dor, ao perigo, e a tudo que é horrível. Para ele, o sublime é uma emoção mais forte que o prazer, pois se remete a uma ideia de dor. Referindo-se à arquitetura, Burke identifica, nas grandes dimensões, as características do sublime, sustentando que os arquitetos, quando não fossem possíveis as grandes dimensões, deveriam se deter em criar ilusão de grandeza. Patetta (1997) identifica essas características nas obras dos arquitetos Gilly, Boullée e Piranesi. 
Collins (1978) atribui às primeiras construções pitorescas as casas rurais da Inglaterra, onde a arquitetura rural estava sendo pensada essencialmente como marcação de cenário natural, como uma pintura de paisagem. O autor explica, de forma simplificada, a mudança no conjunto de princípios estéticos, uma vez que a casa deixa de ser um objeto geometricamente disciplinado em harmonia com a paisagem e passa a ser um elemento complementar de composição desta. Assim, a técnica de composição também passa por modificações, uma vez que a edificação não poderia mais ser a resultante da montagem dos espaços internos, devendo compor com seu plano de fundo. Admite-se então que, anteriormente, isso já tinha sido feito em muitas composições clássicas, nas quais as fachadas eram projetadas anteriormente, colocando o ponto principal da discussão não no projeto da fachada, mas sim na composição, de acordo com as novas ideias.

Sobre a questão dos valores tradicionais, Collins (1978) assegura que o princípio em que a composição arquitetônica e pictórica deve ser o mesmo levou a uma reversão desses valores. Cita Payne Knight como expressão do radicalismo, que afirmava não haver regras válidas, uma vez que estas estavam ultrapassadas.

Outra noção apontada pelo autor como sendo trazida pelo pitoresco foi a preocupação com a novidade, que até esse ponto tinha um senso pejorativo, uma vez que o clássico não tinha aberturas para a originalidade ou para a invenção. A interpretação de novidade foi dada através dos espaços e também na irregularidade, complexidade e variedade das cenas pitorescas. Payne Knight definiu a complexidade como uma constante novidade e ainda recomendou a assimetria como maneira de o edifício se corresponder com a paisagem de montanhas, gramados e bosques, porque, se temos simetria, sabemos qual lado é o frontal e o centro. Portanto a assimetria nos permite essa relação uniforme com a paisagem.

Para Collins (1978), na prática, a resultante dessa filosofia do pitoresco foi o estabelecimento do gótico entre os anos 1800 e 1860 como estilo das vilas suburbanas. Para Downing (1969), o estilo que chama de "gótico rural" não é único, porém aparece recorrente em sua publicação.

A questão da assimetria e sua consequente irregularidade na planta, demonstrada por Collins (1978), está ligada à funcionalidade, que, por sua vez, foi apontada por Freitas (1994). Os teóricos mais perspicazes não tardaram a perceber as vantagens potenciais decorrentes de tais formas livremente concebidas. Utilidade e pitoresco coincidem, de tal forma que, para o próximo século, provou-se quase impossível distinguir entre os dois.

Em meados do século XIX, Downing (1969) manifesta esses novos ideários de maneira consolidada, por meio de seu livro The Architecture of coutry houses. Ele escreve de maneira simples, pois dedica seu livro ao povo americano e quer, por meio da publicação, auxiliar na formação do gosto popular da nação.

Downing (1969) afirma, portanto, que a população deve desenvolver ideias de beleza, harmonia e significados morais no 
dia a dia. Para isso, suas casas devem contem os ideários da beleza, verdade, devendo elevar e purificar os sentimentos. Assegura, ainda, que um "gosto correto" é o resultado de uma educação, o sentimento deve ser guiado por julgamentos.

A fim de proporcionar uma guia para esse "gosto correto", Downing (1969) propõe a discussão de três elementos que julga como base do significado da arquitetura: a utilidade, a beleza e a verdade.

As regras da utilidade, para o autor, são: os custos das edificações não devem exceder os meios dos proprietários; deve haver qualidade nos materiais e na mão de obra empregada nas construções; e, por fim e mais importante, é a conveniência. A casa deve ter conforto e atender à demanda de utilização de seus proprietários, e essa é a regra mais importante. Ele ainda coloca que, na arquitetura perfeita, nenhum princípio de utilidade deve sacrificar a beleza, mais elevar e enaltecer esta.

Defende que a beleza na arquitetura pode ser dividida em dois tipos: absoluta e relativa. A beleza absoluta se encontra na expressão de formas materiais. As típicas ideias dessa beleza são: proporção (relação individual da parte com o todo), simetria (eixo central conectado a duas outras partes, ideia de regularidade e uniformidade), variedade, harmonia e unidade. Já a beleza relativa mostra as qualidades da simples e absoluta beleza, as fontes do prazer que é comumente chamado de beleza da forma. A beleza relativa é aquela que expressa ideia peculiar, moral, social ou intelectual, e também é chamada de beleza da expressão. $\mathrm{Na}$ arquitetura, é aquela que expressa as ideias humanas.

Ainda sobre a questão da beleza, Downing (1969) afirma que, apesar de os críticos separarem beleza do pitoresco, na arquitetura, elas podem estar misturadas. A ideia de beleza, em arquitetura, está relacionada a formas materiais, a ideia do pitoresco de beleza é manifestada como algo rude, violento e difícil. O efeito do todo é algo espirituoso e agradável, mas as partes não são balanceadas, as proporções não são perfeitas, e os detalhes não são rudes. No primeiro olhar do pitoresco, sobrepõe-se a ideia de poder sobre a de beleza. Como a regularidade e a proporção são ideias fundamentais da beleza absoluta, o pitoresco vai achar forma nas condições contrárias, irregularidade, e desejo parcial de proporção e simetria. Importante ressaltar sua visão de como o pitoresco denota poder e como a beleza da expressão forte predomina sobre a pureza da beleza material, e ainda que para o arquiteto conseguir combinar arquitetura rural com cenário rural, é necessário que este entenda, ao menos, um pouco da natureza destes dois.

Downing (1969) considera que a arquitetura aborda o senso do coração, e a verdade na arquitetura é o que controla o julgamento do homem sobre isso. A arquitetura pode ser útil, pode ser bela e ainda assim não ser satisfatória, a menos que seja verdadeira a seu significado. O intelecto tem que aprovar o que o senso e o coração amam. O autor define alguns tipos de verdade: general truth, o edifício deve parecer uma habita- 
ção; local truth, no sentido de espalhar-se pelo vasto território ao em vez de adensar e verticalizar; e specific truth, em que devemos precaver de desperdiçar a beleza e a simplicidade das construções menores para que não seja feita a imitação da riqueza e variedade de outros tipos de edificações.

Downing (1969) separa as construções rurais em três classes: cottages, farm-houses e villas. As edificações caracterizadas como cottage são habitações pequenas, nas quais se predomina a simplicidade: a simples maneira de viver, a economia simples de construir e um gosto simples de decoração; em harmonia com o dia a dia de seus moradores. Farm-houses representam a maioria das edificações rurais nos Estados Unidos e são caracterizadas pela união da simplicidade com o espaço. O autor lamenta encontrar tantas edificações dessa classe que não são satisfatórias com o preceito de não ter recursos para ornamentos, e destaca que a ornamentação não tem importância, uma vez que a arquitetura pode ser bela apenas pela exibição de suas formas. Por outro lado, a villa é considerada uma edificação que representa o ideal de vida. Apesar de serem grandes edificações, são une familiares e devem manifestar individualidade, apresentando as virtudes sociais e os ideais de seus moradores. Deve ainda demonstrar um gosto apurado, um conhecimento profundo sobre a cultura e ser uma construção pensada segundo os preceitos do novo mundo, uma casa onde a humanidade e a república são mais poderosas que o orgulho da família e do sentimento de aristocracia, representando o cidadão virtuoso.

A questão do pitoresco está, portanto, relacionada ao conceito de beleza para o autor, e é debatida nas três classes de edificações. Em caso de edificações muito pequenas, como as cottages, o elemento pitoresco, em vez de estar no objeto, pode estar na sua implantação, na sua composição com a paisagem; nas farm-houses, indica o aparecimento do pitoresco em alguns elementos da composição, como altos telhados, por exemplo; mas é nas villas que encontra sua maior expressão no pitoresco, por meio do homem imaginativo, na assimetria e na variedade das formas.

Cabe, finalmente, uma última ressalva: a de que o pitoresco não é um estilo. Para Patetta (1997), o pitoresco, bem como o sublime, é um particular ponto de vista, que condiciona a eleição figurativa e que não pode ser ignorado por nenhum artista depois da segunda metade do século XVIII.

\section{$O$ reconhecimento do pitoresco nas casas rurais do Oeste Paulista}

Para Freitas (1994), a casa rural da região de Ribeirão Preto, durante o período de 1874 a 1930, buscou o processo de modernização, recebeu a influência burguesa, os novos padrões de conforto, de privacidade, de moda, de racionalidade e de técnica. A autora afirma que a casa mudou na posição em relação a outros edifícios, na técnica construtiva, na divisão e nos diversos elementos. Como expressão da racionalidade, Freitas (1994) aponta a funcionalidade das formas geométricas. 
A primeira comparação que podemos estabelecer nas transformações da arquitetura rural pela presença da sensibilidade pitoresca é justamente na funcionalidade das formas geométricas e, em especial, na preferência pela assimetria. Para demonstrá-la pode-se estabelecer um paralelo entre a Fazenda Figueira e a Fazenda Boa Vista. A primeira localiza-se no Município de Varginha, no Estado de Minas Gerais, e pertence a um período anterior ao do estabelecimento da cafeicultura nas fazendas do Oeste do Estado de São Paulo, sendo sua data possível de construção o início de século XIX. A Fazenda Boa Vista localiza-se no Município de Ribeirão Preto, no Estado de São Paulo, portanto, dentro da zona do Oeste Paulista, pertencendo ao movimento da Marcha Pioneira, como definiu Monbeig (1984). Sua possível data de construção é a última década do século XIX.
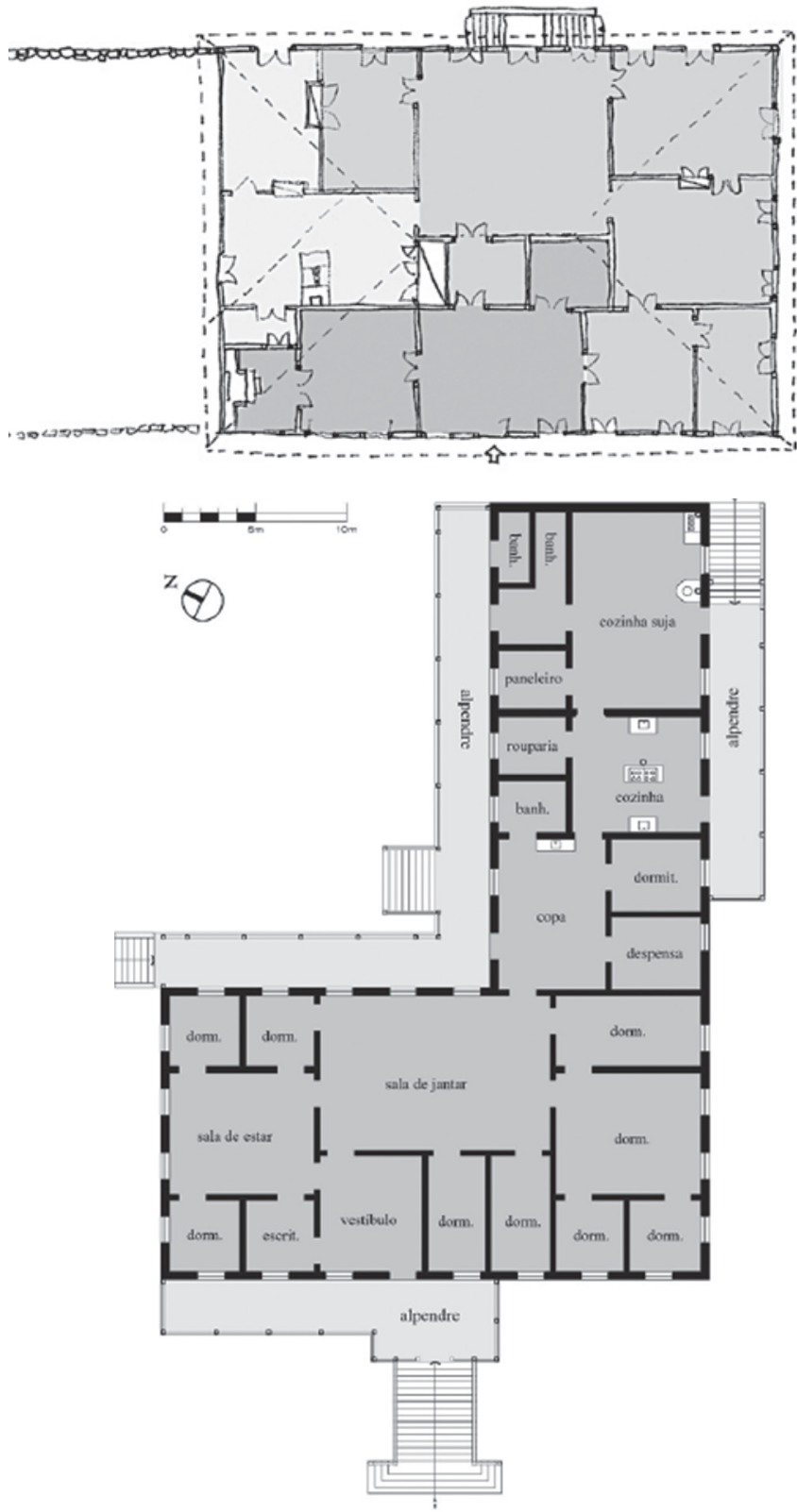

Figura 2 • Planta da casa sede da Fazenda Figueirinha, localizada no Município de Varginha, Minas Gerais. Fonte: Cruz, 2008.

Figura 3 • Planta da casa sede da Fazenda Boa Vista, localizada no Município de Ribeirão Preto, São Paulo. Fonte: Benincasa, 2008. 
Em ambas as plantas, podemos observar a existência da provável distribuição do programa em áreas sociais, de serviço e íntima; mas a maneira como o programa se distribui e o conjunto se arranja se diferencia. A planta da Fazenda Figueira é contida em um retângulo, seguindo os preceitos clássicos da simetria e do equilíbrio de proporções. As áreas compreendidas na tonalidade mais escura correspondem ao uso social e se localizam apenas na parte frontal da edificação; as áreas na tonalidade intermediária são de convívio íntimo e está localizada à direita da habitação, e finalizando, à esquerda, encontram-se os ambientes de serviço. A edificação não tem corredor de distribuição e tem duas alcovas.

Já a planta da Fazenda Boa Vista organiza-se numa figura composta, formada por dois volumes adoçados formando um $L$, que pode ser compreendida como incluindo um corpo principal e uma ala em prolongamento, no lado sudeste. No corpo principal, estão as áreas sociais e íntimas, não há a presença de alcovas, mas ainda retrata a inexistência de corredores, já que os dormitórios se abrem para as salas sociais, que definem centros de convergência. A ala sudeste se conecta ao corpo principal por uma estreita passagem e abriga os serviços, configurando um maior desejo de separação entre o íntimo e social e as áreas de serviço. Cruz (2008) afirma que, no decorrer do século XIX, a planta em $L$ se torna a mais difundida e adotada nas construções rurais, afirmando ser a planta mais característica daquele século.

Outros exemplos de sedes de fazendas poderiam ser citados, corroborando essa transformação das plantas. Mas não é apenas na das plantas que os traços da sensibilidade pitoresca podem ser encontrados na arquitetura rural do Oeste Paulista. Há também uma caracterização estilística das superfícies verticais, que pode ser observada pela análise da composição das fachadas e por seus ornamentos.

Para exemplificá-la, recorremos novamente à comparação de duas fazendas. Uma que está localizada no Oeste Paulista, Fazenda São Sebastião, construída em 1896; a outra, localizada no Município de Bananal, ou seja, pertencente à primeira ocupação do café no Estado de São Paulo, na região do Vale do Paraíba, a Fazenda Resgate, construída em 1828 e reformada em 1850.

Para essa análise, foi escolhida propositalmente a Fazenda São Sebastião, por sua planta quadrada, que não define uma forte separação entre as áreas sociais, íntima e de serviço, sendo bastante simétrica; como também é o caso da Fazenda Resgate. Isso permite compará-las, e ademais, chamar a atenção para a diferenciação estética nas composições das fachadas e presença ou não de ornamentação.

Parece muito evidente a aproximação da Fazenda São Sebastião com a sensibilidade do pitoresco, em especial no desenho e no recorte do telhado, bem como em seu suporte ornamentado e revestido de madeira. Downing (1969) afirma que o pitoresco na composição arquitetônica é a manifestação da beleza por meio do poder. Portanto tudo o que transmite a ideia de força por meio da forma adquire o pitoresco nela, garantindo ainda que o caráter da expressão pitoresca pode ser, muitas vezes, encontrado no projeto de cobertura. 

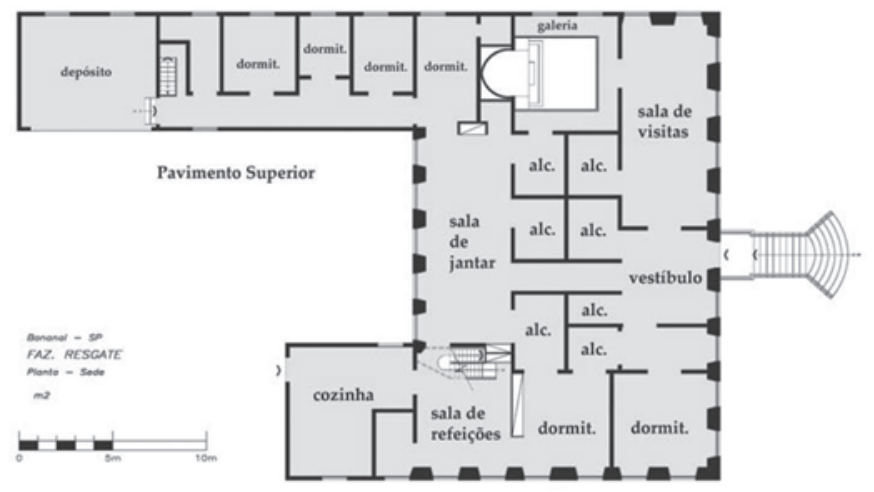

Figura 4 - Planta e elevação frontal da casa sede da Fazenda Resgate, localizada no Município de Bananal, São Paulo. Fonte: Benincasa, 2008.
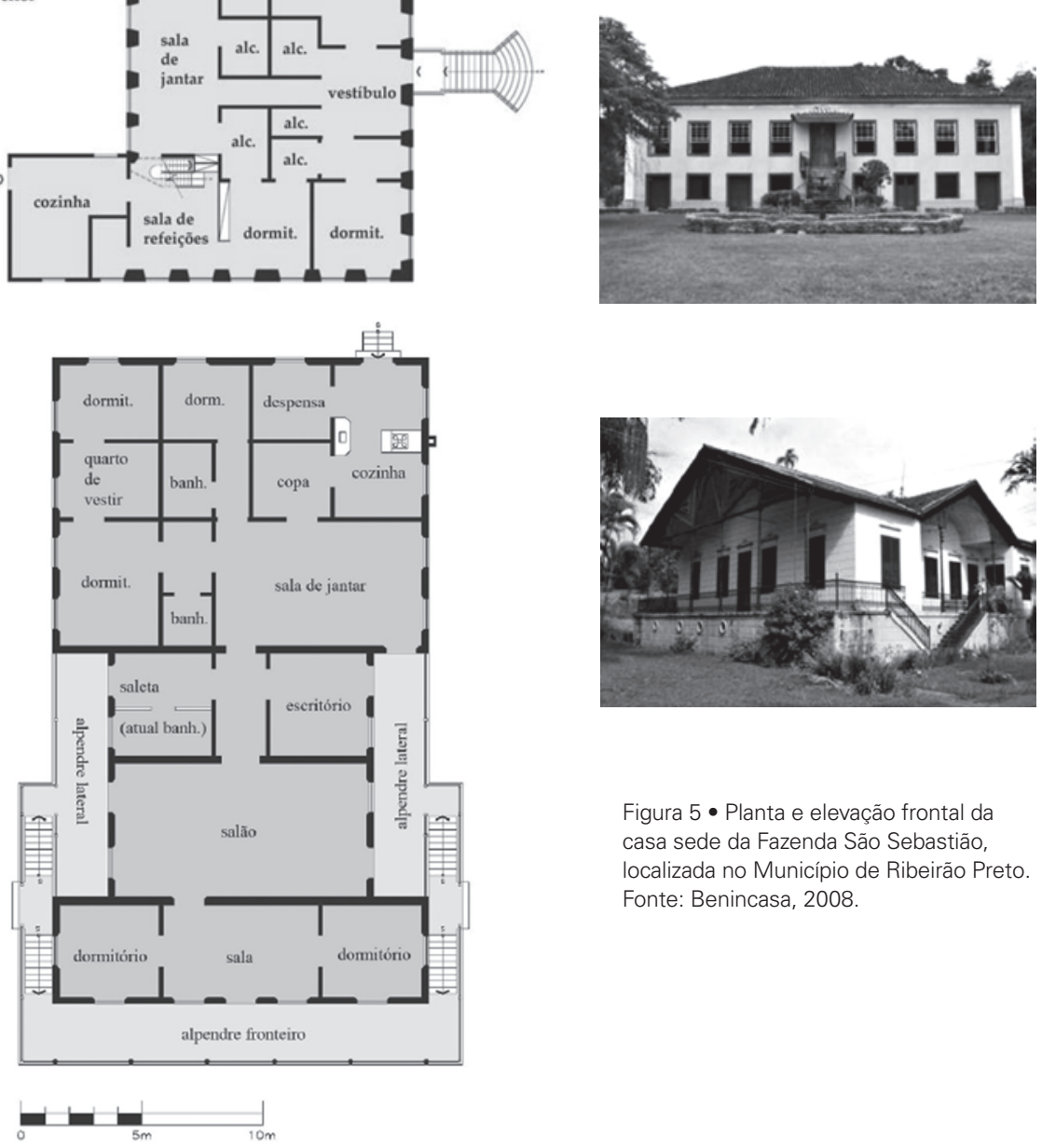

Figura 5 - Planta e elevação frontal da casa sede da Fazenda São Sebastião, localizada no Município de Ribeirão Preto. Fonte: Benincasa, 2008.

Nada foi dito, ainda, do grande valor do projeto de cobertura do tipo de beleza chamado Pitoresco. Mas na verdade, esse é um dos mais simples, barato e eficaz modo de dar forças ao espírito de qualquer edifício. A fonte secreta do Pitoresco é a manifestação de beleza através do poder, e não, como no belo, através da ocultação do poder sob o repouso da aparência externa. Assim, tudo o que transmite a ideia de resistência ou força em alcançar qualquer forma agradável, aumenta o pitoresco daquela forma. (Tradução livre DOWNING, 1969, p. 113)4

Podemos ainda traçar um paralelo entre a Fazenda São Sebastião e o projeto proposto por Downing (1969, p. 150), intitulado A farm-house in the Swiss manner. O autor chama a atenção para o pitoresco e para o pastoril nesse projeto, e ainda para os detalhes que remetem ao estilo do Chalé Suíço, como o fato de ser construído em madeira e ter ornamentação nos suportes do telhado; ambas as características também presentes na Fazenda São Sebastião.

4. We have said nothing, as yet, of the great value of projecting roof in the production of that kind of beauty called the Picturesque. But in fact, this is one of the simplest, cheapest, and most effective modes of giving force and spirit to any building. The secret source of the Picturesque is the manifestation of Beauty through power, not, as in the Beautiful, the concealment of power under the external repose of Beauty. Hence, everything that conveys the idea of strength or force in attaining any agreeable form, adds to the picturesqueness of that form. (DOWNING, 1969, p. 113)

Cadernos de Arquitetura e Urbanismo, v.20, n.26, $1^{10}$ sem. 2013 


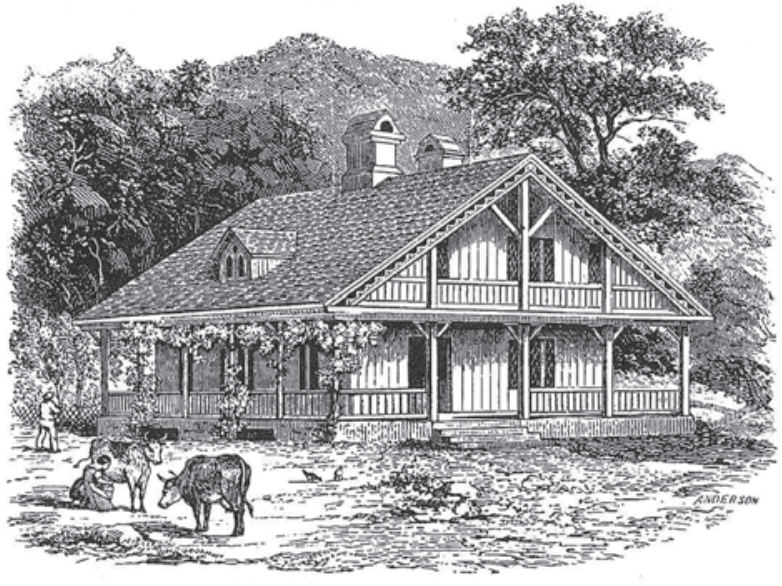

Campos (2008) expõe que a arquitetura denominada "chalé" é fruto do Romantismo do século XIX, tendo concepção ligada ao ideário da vida campestre, dada a sua primeira aparição em 1816. Afirma ainda que, "Em geral, possuía planta retangular e telhado de duas águas, com suave inclinação, disposto de modo a voltar uma das empenas para a frente. Notabilizava-se, sobretudo, pela profusa ornamentação externa" (p. 51). Por meio de sua descrição, permite-nos confirmar o paralelo da Fazenda São Sebastião e a arquitetura denominada "chalé".

Quanto à materialidade das edificações, a Fazenda Resgate de Bananal ainda mantém viva a tradição construtiva colonial, sendo construída em taipa de pilão nas paredes externas e taipa de mão nas divisões internas. Já a Fazenda São Sebastião se trata de uma construção de alvenaria de tijolos, que teve, porém, sua fachada, como mencionado, revestida de madeira, aproximando-se da aparência do "estilo" de arquitetura dito dos chalés suíços (ou mais precisamente, na apropriação acadêmica e erudita da tradição popular suíça).

Em termos de volumetria e composição arquitetônica, um bom exemplar da presença do pitoresco nessa região se trata da Fazenda Guatapará, localizada no Município de mesmo nome. A fazenda, que foi concebida e planejada em 1885, por Martinho Prado Júnior, era uma pequena cidade que abrigava aproximadamente 2000 trabalhadores.

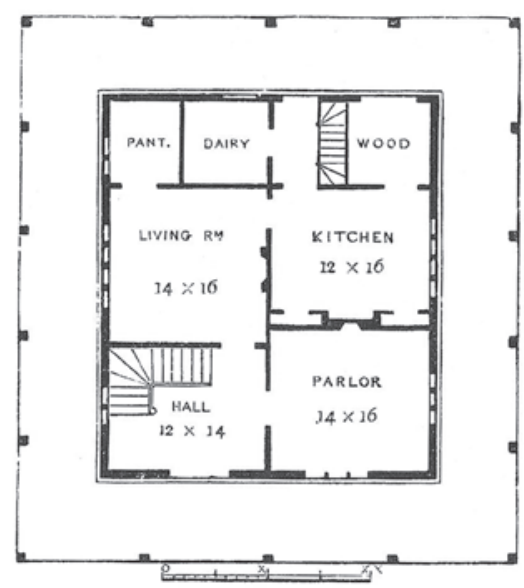

Figura 6 - A Farm-house in the Swiss manner. Fonte: Downing, 1969, p. 150.

Figura 7 - Plantas da casa sede da Fazenda Guatapará. Fonte: Desenho de João Paulo Papandre Lemos, sem data. Disponível em: Site das estações ferroviárias.
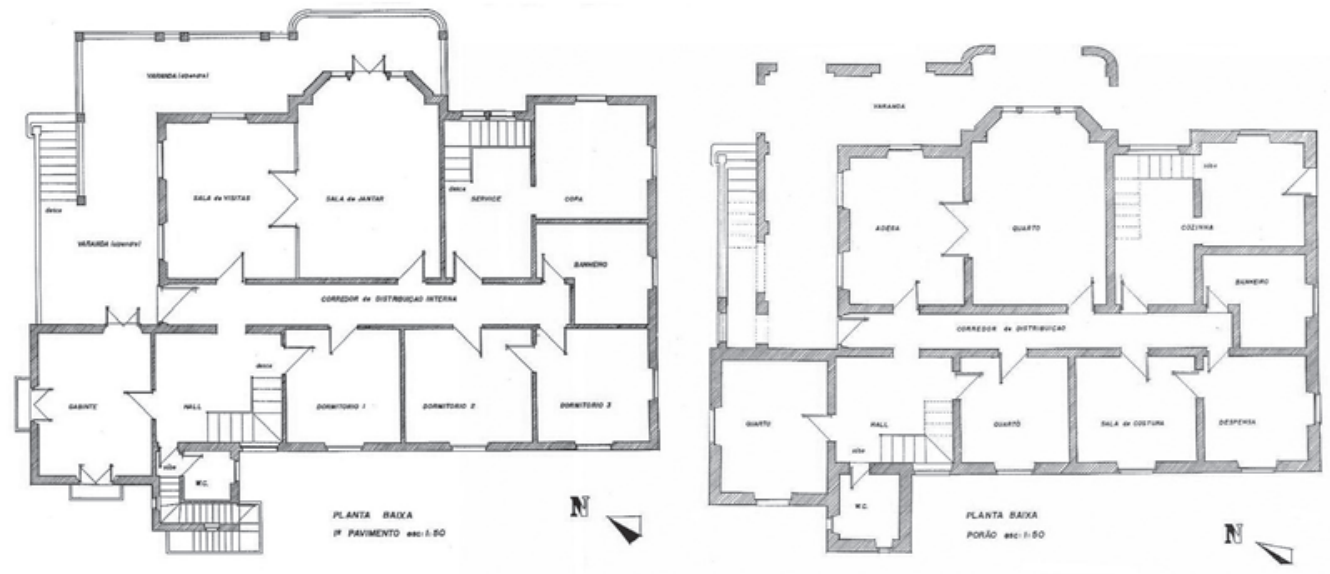
Infelizmente essa fazenda foi demolida, mas, graças a materiais gráficos, podemos fazer uma breve análise sobre suas características pitorescas. Sua planta tinha inovações no programa e na distribuição interna, como, por exemplo, a presença de um corredor de distribuição, organizado os ambientes de maneira linear e assimétrica, característica refletida também em sua fachada. A assimetria e a presença de um pequeno torreão são as primeiras características que se podem notar ao observar essa fachada frontal dessa edificação.

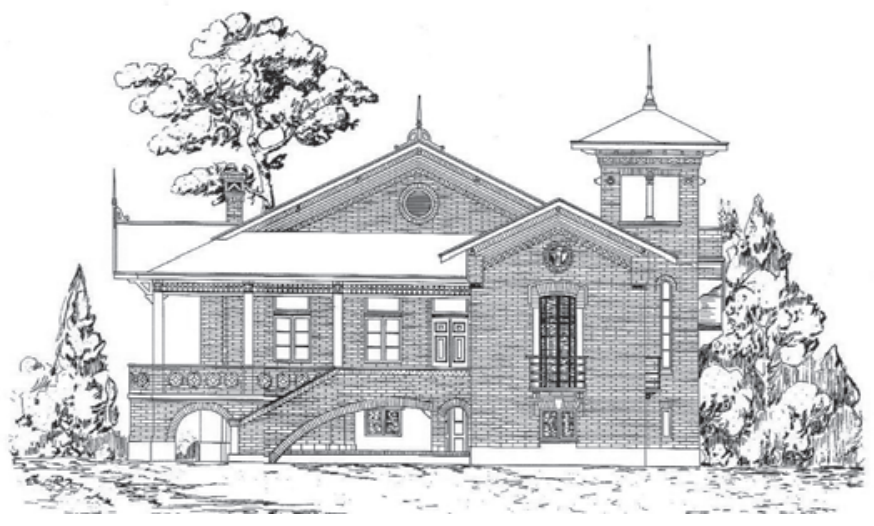

Assim como a Fazenda Boa Vista, essa fazenda também pode ser comparada com um projeto proposto por Downing (1969, p. 343) A lake or river villa for a picturesque site. Diferindo no terreno de implantação, uma vez que o autor propõe ser essa uma habitação para o entorno de um lago ou rio, suas semeIhanças em termos compositivos e formais são grandes. Ambos os projeto têm um corpo central, com uma cobertura de duas águas, ladeados ora por uma varanda de acesso coberta, ora por um pequeno torreão. Downing (1969) afirma que essa torre com telhado íngreme tem o intuito de se relacionar com a paisagem, porque esse formato harmoniza com contraste e com a assimilação do poder e da beleza do cenário romântico.

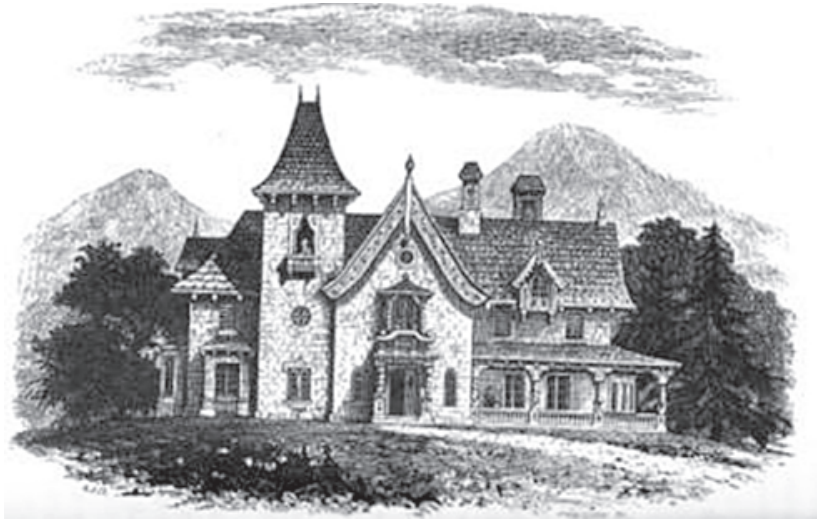

Apesar de a Fazenda Guatapará ter maiores dimensões, suas plantas também são passíveis de comparação, não em suas distribuições externas, mas na suas composições formais com chanfros arrematando os ambientes.
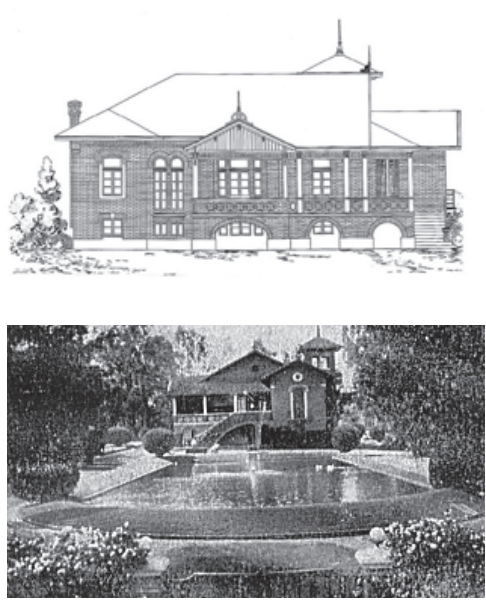

Figura $8 \bullet$ Imagem da fachada frontal e desenhos da fachada frontal e posterior. Fonte: Desenho de João Paulo Papandre Lemos, sem data. Disponível em: Site das estações ferroviárias.

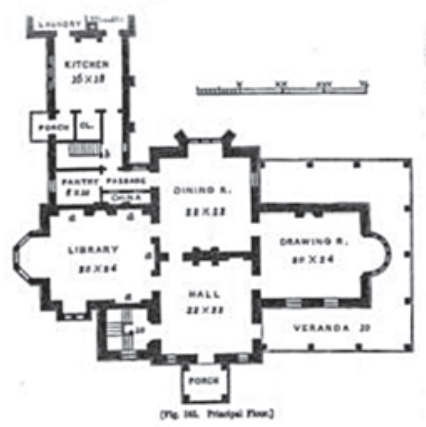

Figura $9 \bullet$ A lake or river villa for a picturesque site. Fonte: Downing, 1969, p. 343. 
Um último aspecto que também remete ao pitoresco que pode ser analisado nessas casas rurais do Oeste Paulista é a questão da ornamentação. Downing (1969, p. 259) entende que não é necessário haver ornamentação para que haja beleza na construção, afirmando que apenas as belas formas puras podem atribuir essa qualidade para as habitações; porém admite que, em diversos projetos, os quais ele julga serem mais refinados, seria possível acrescentar algumas ornamentações, como vergas de borda no estilo gótico rural. Repercussões dessas ideias podem ser encontradas nas fazendas da região Oeste Paulista, que, de maneira semelhante, também apresenta alguns desses detalhes estudados por Downing (1969), como é o caso dos ornatos nos beirais das fazendas Boa Vista e Monte Alegre, no Município de Ribeirão Preto.
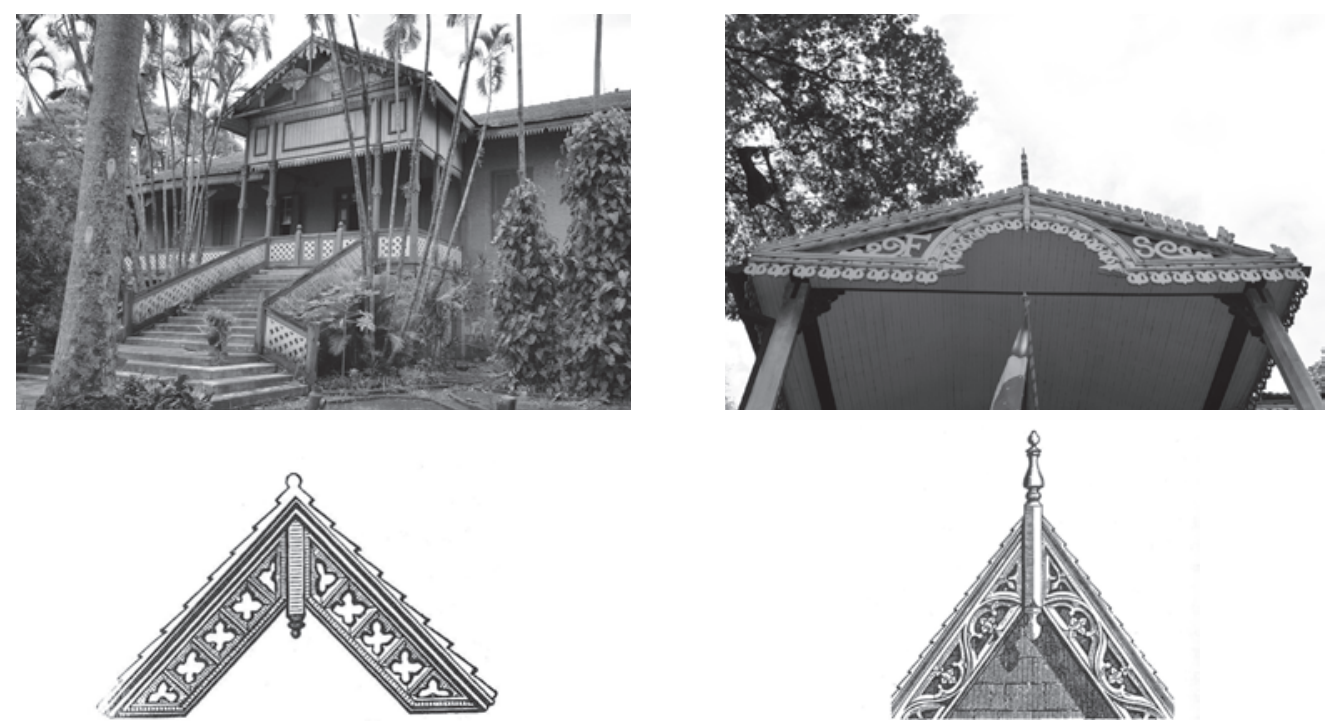

\section{Conclusão}

Tendo em vista a proposta inicial, este estudo atinge seu principal objetivo: analisar as transformações na arquitetura rural do Oeste Paulista no século XIX, considerando, nas sedes de fazendas desse período, o aparecimento do pitoresco.

Na primeira parte de trabalho, foi possível, por meio do estudo do surgimento, contextualização e aplicação do pitoresco, a formação de um quadro referencial teórico. Esses conceitos teóricos abordados foram fundamentais para a execução da segunda parte do trabalho, em que se analisou, de maneira comparativa com períodos anteriores do ciclo cafeeiro, e com projetos proposto pelo arquiteto Downing (1969), o aparecimento do pitoresco na referida arquitetura.

Este artigo afirma, ao longo de seus estudos comparativos, a presença do pitoresco como característica denunciadora das transformações que atravessaram a arquitetura rural do Oeste Paulista. Essa afirmação pode ser concluída com a análise das questões arquitetônicas, de funcionalidade das formas geométricas, composição volumétrica e caracterização estilística, incluindo a questão da ornamentação.

Figura 10 - Comparativo entre os ornatos da Fazenda Boa Vista e da Fazenda Monte Alegre, com os sugeridos por Downing (1969). Fonte: Fotos do arquivo pessoal e imagens retiradas de Downing, 1969, p. 374 e 376. 


\section{Referências}

ARGAN, Giulio Carlo. Arte moderna: do lluminismo aos movimentos contemporâneos. 2. ed. São Paulo: Companhia das Letras, 2006.

BENINCASA, Vladimir. Fazendas paulistas: arquitetura rural no ciclo cafeeiro. 2008. Tese (Doutorado em Teoria e História da Arquitetura e do Urbanismo) - Escola de Engenharia de São Carlos, Universidade de São Paulo, São Carlos.

BENÉVOLO, Leonardo. Historia de la arquitectura moderna. 2. ed. Barcelona: G. Gili, 1974.

CAMPOS, Eudes. Chalés paulistanos. An. mus. paul., São Paulo, v. 16, n. 1, June 2008. Disponível em: <http://www.scielo.br/scielo.php?script=sci_arttext\&pid=S0101-47142008000100003\&lng= en\&nrm=iso>. Acesso em: 7 out. 2012.

CRUZ, Cícero Ferraz. Fazendas do sul de Minas: arquitetura rural nos séculos XVIII e XIX. 2008. Dissertação (Mestrado em Teoria e História da Arquitetura e do Urbanismo) - Escola de Engenharia de São Carlos, Universidade de São Paulo, São Carlos. COLLINS, Peter. Changing ideals in modern architecture, 1750-1950. Montreal: McGill: Queen's University Press, 1978.

DOWNING, Andrew Jackson. The architecture of country houses. New York: Dover, 1969.

FREITAS, Daici Ceribeli Antunes de. Os signos da modernidade nos cafezais. 1994. Tese (Doutorado em Ciências da Comunicação) - Universidade de São Paulo, São Paulo.

FERRÃO, André Munhoz de Argollo. Arquitetura do café. Campinas: Unicamp; São Paulo: Imprensa Oficial do Estado, 2004.

KRUFT, Hanno Walter. A History of Architectural theory from Vitruvius to the present. New York: Princeton Architectural Press, 1994.

MATOS, Odilon Nogueira De. Café e ferrovias: a evolução ferroviária de São Paulo e o desenvolvimento da cultura cafeeira. 3. ed. São Paulo: Arquivo do Estado, 1981.

MONBEIG, Pierre. Pioneiros e fazendeiros de São Paulo. Tradução Ary França e Raul de Andrade e Silva. São Paulo: Hucitec; Polis, 1984.

PATETTA, Luciano. Historia de la arquitectura: antologia critica. Madri: Celeste Ediciones, 1997.

ROCHA-PEIXOTO, Gustavo. Reflexos das Luzes na Terra do Sol. São Paulo: ProEditores, 2000.

SAIA, Luiz. Morada paulista. São Paulo: Perspectiva, 1972.

Site das estações ferroviárias: http://www.estacoesferroviarias. com.br/lugaresesquecidos/faz_guatapara.htm. Acesso em: 7 out. 2012.

\section{Endereço para correspondência}

Ana Carolina Gleria

Rua Adolfo Serra, 1724

14025-520 - Ribeirão Preto-SP

E-mail: anacarolinagleria@hotmail.com 